\title{
Research on Influencing Factors of Composite Foundation Settlement with Capped Pipe Piles Based on Centrifugal Model Test
}

\author{
Yao Bei-bei ${ }^{1}$,Zhao Li-ping ${ }^{1}$,Pan Chun-feng ${ }^{1}$ \\ ${ }^{1}$ Zhongyuan University Of Areonautics, School of Civil Engineering, Zhengzhou, 450015
}

\begin{abstract}
In order to study the influence of design factors of capped pipe pile composite foundation on differential settlement of expressways, using a geotechnical centrifugal model test platform, a centrifugal model of widen roadbed has been constructed. The effects of pile length, pile spacing, pile cap and cushion thickness on differential settlement were analyzed through comparative experiments. The test results show that increasing the pile length, pile cap size and cushion thickness can effectively control the differential settlement between old and new embankments. The research results can provide a theoretical basis for the design of composite foundations with capped pipe piles.
\end{abstract}

\section{Introduction}

The efficiency and advantages of the pipe pile composite foundation have been recognized in the construction engineering and it has also been applied in the flexible foundation such as embankment.

Some scholars have carried out researches on this problem. Zou Yongqiang [1] analyzed the working behavior of rigid pile composite foundation and the factors affecting its settlement, based on which, he found there are problems in the study of the working behavior of rigid pile composite foundation. Sharma ${ }^{[3]}$ confirmed the influence of the cushion on the axial force and shear force of the pile body through the rigid long-short pile raft composite foundation. Zeng Juncheng ${ }^{[6]}$ studied the effect of pile cap on the settlement of composite foundation by numerical model and he found that the diameter of pile cap could increase the pile-soil stress ratio and reduce settlement and settlement difference between pile and soil. The relationships among design parameters such as pile length, pile spacing and pile cap size are studied by Lei Jinbo ${ }^{[7]}$ and he put forward the optimum design.

On the basis of previous studies, the centrifugal model test of composite foundation with capped pipe pile is established and the monitoring means are upgraded to analyze the influence of design factors such as pile length, pile spacing, pile cap size, cushion material and thickness on the settlement of composite foundation, which will provide a basis for the design of pipe pile composite foundation.

\section{Scheme Design of the Centrifuge Model Test}

\subsection{Test Plan}

The test equipment is the TLJ-3 geotechnical centrifuge with the maximum capacity of $60 \mathrm{gt}$, effective radius of $2 \mathrm{~m}$, model box size of $740 \mathrm{~mm} \times 560 \mathrm{~mm} \times 460 \mathrm{~mm}$ and it has 40 channels of strain, voltage and temperature. The test will simulate the application of capped pipe pile composite foundation in the reconstruction and expansion project of expressways. And the influence of design parameters, such as pile length, pile spacing and pile cap size on the settlement is analyzed by the contrast test. The original embankment is $10 \mathrm{~m}$ wide, the fill is $8 \mathrm{~m}$, the gradient is $1: 1.2$, and the width is $7 \mathrm{~m}$. The depth of the foundation is $16.2 \mathrm{~m}$ and there are two layers. The thickness of the upper clay is $10 \mathrm{~m}$ while the lower sand is $6.2 \mathrm{~m}$. The diameter of pipe pile is $600 \mathrm{~mm}$, the length of pile is $10 \mathrm{~m}$, and the length of pile cap is $1000 \mathrm{~mm}$. According to the calculation model ratio $\mathrm{N}=60$, the test scheme is shown in Fig1.

\footnotetext{
* Corresponding author: yaobei321@126.com
} 


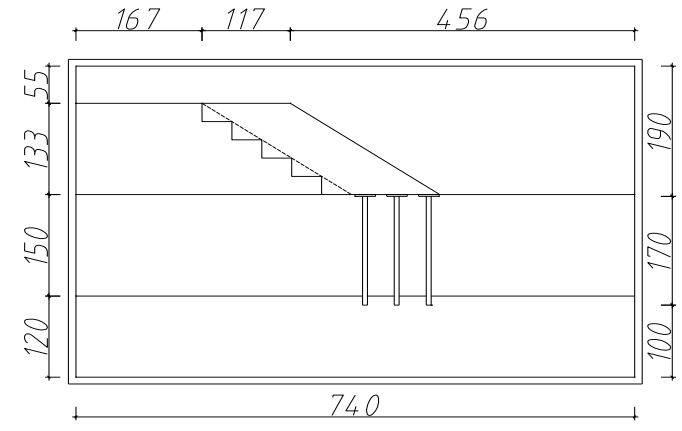

Fig.1 Schematic diagram of model test for pipe pile composite foundation

\subsection{Model Piles}

The diameter of pipe pile is $600 \mathrm{~mm}$. According to the model similarity ratio test, the pipe pile model should be $600 / 60=10 \mathrm{~mm}$. It is difficult to manufacture reinforced concrete piles with $10 \mathrm{~mm}$ diameter, so we consider to replace them with materials with similar mechanical properties. According to the similitude ratio of centrifugal model test, the similitude constant of elastic modulus is 1 , so the material that has the similar elastic modulus of the pipe pile will be selected and the shape of it should be the same as that of the pipe pile. After comparing six kinds of annular cross-section materials (PVC, plastic, bakelite, copper, aluminum alloy and stainless steel), thin-wall stainless steel pipe with diameter of $10 \mathrm{~mm}$ is selected to make the model pile.

The pile cap of the prototype is $1.5 \mathrm{~m} \times 1.5 \mathrm{~m} \times 0.5 \mathrm{~m}$, $\mathrm{E}=28 \mathrm{GPa}$. The material used in the simulation should be the same as that of the model pile. According to the similarity principle of bending stiffness, the model and prototype should meet the following requirements:

$$
\frac{E_{p}}{N^{4}} \times \frac{b_{p} h_{p}^{3}}{12}=E_{m} \times \frac{b_{m} h_{m}^{3}}{12}
$$

\subsection{Preparation of Model Soil}

The prototype soil is used to simulate the clay layer above the foundation. The effective particle size of the soil should be less than 0.002 , the limited particle size is 0.02 , and the coefficient of non-uniformity is more than 10 , which is the well-graded soil. The liquid limit is 28 , plastic limit is 16 , plastic index is 12 and liquid index is 0.41 . It's confirmed by the test that the optimum moisture content is $13.9 \%$ and the maximum dry density was $1.83 \mathrm{~g} / \mathrm{cm} 3$. The allocation process of the soil sample should be strictly based on the optimum moisture content and the maximum dry density. The other physical properties are shown in Table 1.

Table 1 Test the physical index of soil sample

\begin{tabular}{|c|c|c|c|c|c|c|c|}
\hline $\begin{array}{c}\text { Porosity } \\
\text { Ratio e }\end{array}$ & $\begin{array}{c}\text { Satura } \\
\text { tion \% }\end{array}$ & $\begin{array}{c}\text { Dry } \\
\text { Density } \\
\mathrm{g} / \mathrm{cm} 3\end{array}$ & $\begin{array}{c}\text { Wet } \\
\text { Density/ } \\
\mathrm{g} / \mathrm{cm} 3\end{array}$ & $\begin{array}{c}\text { Natural } \\
\text { Water/ } \\
\%\end{array}$ & $\begin{array}{c}\text { Plastic } \\
\text { Limit } \\
\mathbf{\%})\end{array}$ & $\begin{array}{c}\text { Liquid } \\
\text { Limit } \\
(\%)\end{array}$ & $\begin{array}{c}\text { Plasticit } \\
\text { y Index }\end{array}$ \\
\hline 1.85 & 18.62 & 1.39 & 1.57 & 12.84 & 18 & 29 & 11 \\
\hline
\end{tabular}

The physical properties of the second layer of sand are shown as: natural porosity ratio $\mathrm{e}=0.73$, dry density $\rho d=1.45 \mathrm{~g} / \mathrm{cm} 3$ and saturation density $\rho s a t=1.65 \mathrm{~g} / \mathrm{cm} 3$, which is disposed by the method of rainfall. The standard sand required is $48.6 \mathrm{~kg}$ according to the calculation. Based on the calibration curve of relative density, the distance should be $55 \mathrm{~cm}$ when the density is $60 \%$. The preparation process is as follows: drying the model sand, preparing the equipment such as the leaking head, hose, sand bucket and so on. Moreover, the height of the leaking head is set to $55 \mathrm{~cm}$. We should also place the model box and pour the sand in six layers, each layer $20 \mathrm{~cm}$ and altogether $120 \mathrm{~cm}$.

\subsection{Placement of the Test Sensor}

(1) Inner Settlement Monitoring of Subgrade

In order to monitor the deformation of the soil in the roadbed, a high-speed video camera and markers are used to monitor the deformation. The placement of the markers is shown in Fig. 2. Five rows are arranged in the embankment. The first row is $15 \mathrm{~mm}$ away from the surface of the roadbed while the row spacing is $20 \mathrm{~mm}$ and the column spacing is $40 \mathrm{~mm}$. The first row is $10 \mathrm{~mm}$ away from the surface of the foundation, the row spacing is $25 \mathrm{~mm}$, and the column spacing is $45 \mathrm{~mm}$.

(2) Monitoring of the Total Settlement of Subgrade

The total settlement of roadbed is monitored by NCDT1300 laser displacement sensor. Three laser displacement sensors, $\mathrm{C} 1, \mathrm{C} 2$ and $\mathrm{C} 3$, are set up according to the test conditions, as shown in Fig. 2.

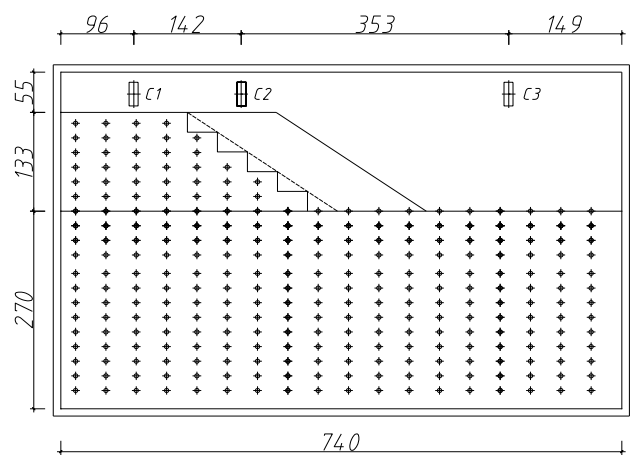

Fig 2 Settlement monitoring layout

(3) Strain Monitoring

Taking the $10 \mathrm{~m}$ pipe pile model as an example, the arrangement of the sensors is shown in Fig. 3.

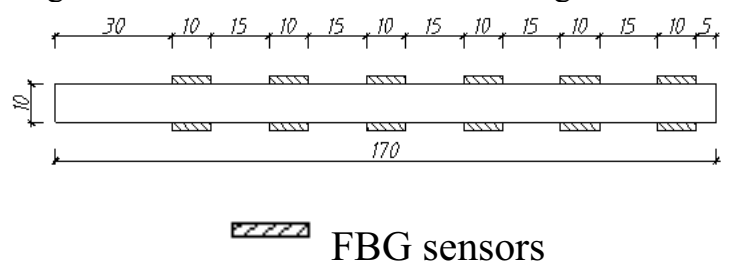

Fig 3 The layout of fiber Bragg grating sensors

\subsection{Test Steps}

The experiment is conducted in four groups. The first group of tests is the natural foundation one, which simulates the widening of subgrade on the natural foundation. The test begins with filling the foundation and the old roadbed. After 8 years of operation, the 
machine will stop. Then we will dig steps on the old embankment and fill it to widen the embankment. The widened embankment is filled and operated for 3 years. Then the test will be finished. During the test, the settlement of subgrade is observed. The second group is the pile length influence test, which is carried out 5 times. Pipe piles are used to fix the old subgrade after 8 years operation of filling foundation and the old subgrade. The length of pipe pile models should be $100 \mathrm{~mm}, 134 \mathrm{~mm}$, $170 \mathrm{~mm}, 200 \mathrm{~mm}$ and $234 \mathrm{~mm}$ long that are equivalent to the actual pile length of $6 \mathrm{~m}, 8 \mathrm{~m}, 10 \mathrm{~m}, 12 \mathrm{~m}$ and $14 \mathrm{~m}$. The distance between piles is $1.8 \mathrm{~m}$ (3.0d), the pile cap is $1.0 \mathrm{~m}$, and the sand cushion is $0.6 \mathrm{~m}$ on the pile top. After the foundation treatment, the old embankment is widened by excavation steps, and the operation of the embankment is stopped after 3 years. The third group is the replacement rate test. The test process is basically the same as that of the second group. The pile length is $10 \mathrm{~m}$ and the pile spacing is $1.8 \mathrm{~m}(3.0 \mathrm{~d}), 2.4 \mathrm{~m}(4.0 \mathrm{~d}), 3.0 \mathrm{~m}$ (5.0d) and $3.6 \mathrm{~m}(6.0 \mathrm{~d})$ respectively, which is used to study of the effect of the pile spacing on the settlement. The fourth group is pile cap test and the process is basically the same as that of the second group, but the length of pile caps is $80 \mathrm{~cm}, 100 \mathrm{~cm}$ and $120 \mathrm{~cm}$ respectively. The fifth group is the cushion thickness test and the test process is basically the same as that of the second group, but the cushion material is lime-soil cushion and crushed stone one. The cushion thickness is $0.4 \mathrm{~m}, 0.6 \mathrm{~m}, 0.8 \mathrm{~m}, 1.0 \mathrm{~m}$ and $1.2 \mathrm{~m}$ respectively.

\section{Analysis of Factors That Affect Settlement}

\subsection{Effects of Pile Length}

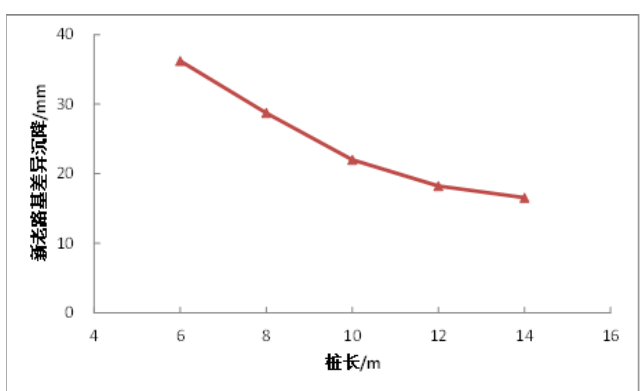

Fig. 6 Influence of pile length on differential settlement

Fig. 6 shows the effect of pile length on differential settlement. From Fig. 6, it can be shown that the pile length has a great influence on the differential settlement of both the new and old subgrade: when the pile length increases from $6 \mathrm{~m}$ to $14 \mathrm{~m}$, the differential settlement decreases from $36.21 \mathrm{~mm}$ to $16.56 \mathrm{~mm}$, with a decrease of $54 \%$. When the pile length reaches $10 \mathrm{~m}$, the differential settlement decreases slowly, but the differential settlement changes little when the pile length increases to $12 \mathrm{~m}$ and $14 \mathrm{~m}$. It can be known that increasing the pile length within a certain range can better reduce differential settlement. However, when the increasing pile length goes beyond a certain range, it won't get better treatment effect. Therefore, the optimum pile length should be determined in engineering projects.

\subsection{Effects of Pile Spacing}

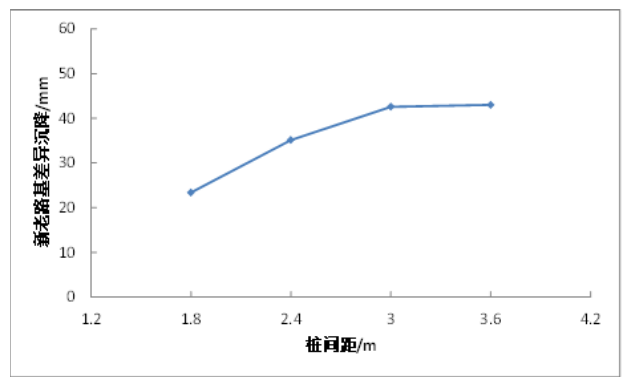

Fig 7 Influence of pile spacing on differential settlement

The effect of pile spacing on differential settlement is shown in Fig. 7. From Fig. 7, it can be known that with the increase of pile spacing, the differential settlement of new and old subgrade increases gradually. When the pile spacing increases from 3-time pile diameter $1.8 \mathrm{~m}$ to 4-time pile diameter $2.4 \mathrm{~m}$, the differential settlement increases from $23.4 \mathrm{~mm}$ to $35.13 \mathrm{~mm}$, with an increase of $50 \%$. When the pile spacing continues to increase to 5-time and 6-time pile diameter, the differential settlement increases slowly and tends to be stable. Considering the effect of settlement control and economy, it is reasonable to use the 4-time pile spacing.

\section{Conclusion}

From the results of the test, we can know that increasing pile length,can effectively control differential settlement while reducing pile spacing can also achieve a good effect. However, there is an optimum length for piles. When the increase of pile length goes beyond the optimum length, it will have little effect on differential settlement.

\section{The Fund Projects}

The name of fund: Theoretical Study on Deformation Control of Composite Foundation of Widening Roadbed Control Pipe Pile.

Fund project number: 192102310230

\section{Reference}

1. Yongqiang Zhou, Jinbo Lei, Yansong Yang. Research progress and analysis on working behavior of rigid pile composite foundation[J]. Journal of Nanchang Hangkong University. 2019,33(4):45-51.

2. Juncheng Zeng. Numerical analysis of pile cap action in composite foundation and calculation of pile cap bearing capacity $[\mathrm{J}]$. The subgrade engineering, 2012(2):34-37.

3. Jinbo Lei,Pengpeng,Chaoqun Chen. Design and application of composite foundation with rigid pile cap[J]. Journal of Nanchang Hangkong University, 2011,25(1):88-92. 
4. Sharma V J,Vasanvala,Solanki C H. Behaviour of cushioned composite piled raft foundation under lateral forces $[\mathrm{J}]$. Indian Geotechnical Journal, 2015,45(1):89-97. 